Fixed Point Theory, 21(2020), No. 2, 561-584

DOI: $10.24193 /$ fpt-ro.2020.2.40

http://www.math.ubbcluj.ro/ nodeacj/sfptcj.html

\title{
VISCOSITY METHOD WITH A $\phi$-CONTRACTION MAPPING FOR HIERARCHICAL VARIATIONAL INEQUALITIES ON HADAMARD MANIFOLDS
}

\author{
SULIMAN AL-HOMIDAN*, QAMRUL HASAN ANSARI**, FEEROZ BABU*** \\ AND JEN-CHIH YAO**** \\ *,** Department of Mathematics and Statistics, \\ King Fahd University of Petroleum and Minerals, Dhahran, Saudi Arabia \\ E-mail: homidan@kfupm.edu.sa \\ **,*** Department of Mathematics, Aligarh Muslim University, Aligarh, India \\ E-mail: qhansari@gmail.com \\ and \\ *** Present Address: National Sun Yat-sen University, Kaohsiung, Taiwan, ROC \\ E-mail: firoz77b@gmail.com \\ **** Department of Mathematics, Zhejiang Normal University, Jinhua, China \\ E-mail: jen-chih.yao@zjnu.edu.cn (Corresponding author)
}

\begin{abstract}
In this paper, we propose the viscosity method for solving variational inequality problems defined over a set of fixed points of a nonexpansive mapping and involving a $\phi$-contraction mapping and another nonexpansive mapping in the setting of Hadamard manifolds. Several special cases of such a variational inequality problem are also considered. The convergence analysis of the proposed method is studied. We illustrate proposed algorithm and convergence result by a numerical example. The algorithms and convergence results of this paper extend and improve several known algorithms and results from linear structure to Hadamard manifolds.

Key Words and Phrases: Viscosity method, $\phi$-contraction mappings, hierarchical variational inequality problem, Moreau-Yosida regularization, hierarchical minimization problem, Hadamard manifolds, monotone vector fields, geodesic convexity, nonexpansive mappings.
\end{abstract}

2010 Mathematics Subject Classification: 58E35, 58C30, 47H10, 49J53, 47J20, 47J25.

Acknowledgements. First and second author are thankful to KFUPM, Dhahran, Saudi Arabia for providing excellent research facilities to carry out their part of research work. The research of Jen-Chih Yao was partially supported by the Grant MOST 108-2115-M-039 -005 -MY3. Authors are grateful the editor Prof. Adrian Petrusel and the anonymous referee for their valuable suggestions that improved the previous draft of the paper. 


\section{REFERENCES}

[1] Y.I. Alber, S. Guerre-Delabriere, Principles of weakly contractive maps in Hilbert spaces, Oper. Theory Adv. Appl., 98(1997), 7-22.

[2] S. Al-Homidan, Q.H. Ansari, F. Babu, Halpern and Mann type algorithms for fixed points and inclusion problems on Hadamard manifolds, Numer. Funct. Anal. Optim., 40(6)(2019), 621-653.

[3] Q.H. Ansari, F. Babu, Proximal point algorithm for inclusion problems in Hadamard manifolds with applications, Optim. Lett., (2019), DOI: 10.1007/s11590-019-01483-0.

[4] Q.H. Ansari, F. Babu, X.-B. Li, Variational inclusion problems in Hadamard manifolds, J. Nonlinear Convex Anal., 19(2)(2018), 219-237.

[5] M. Bačák, Computing medians and means in Hadamard spaces, SIAM J. Optim., 24(2014), $1542-1566$.

[6] D.W. Boyd, J.S. Wong, On nonlinear contractions, Proc. Amer. Math. Soc., 20(1969), 335-341.

[7] M. Bridson, A. Haefliger, Metric Spaces of Non-positive Curvature, Springer-Verlag, Berlin, Heidelberg, New York, 1999.

[8] A. Cabot, Proximal point algorithm controlled by a slowly vanishing term: applications to hierarchical minimization, SIAM J. Optim., 15(2005), 555-572.

[9] J.X. da Cruz Neto, O.P. Ferreira, L.R. Lucambio Pérez, Monotone point-to-set vector fields, Balkan J. Geometry Appl., 5(1)(2000), 69-79.

[10] J.X. da Cruz Neto, O.P. Ferreira, L.R. Lucambio Pérez, S.Z. Németh, Convex- and monotonetansformable mathematical programming problems and a proximal-like point method, J. Global Optim., 35(2006), 53-69.

[11] M.P. do Carmo, Riemannian Geometry, Birkhäuser, Boston, Basel, Berlin, 1992.

[12] O.P. Ferreira, P.R. Oliveira, Proximal point algorithms on Riemannian manifolds, Optimization, 51(2002), 257-270.

[13] S. Huang, Approximations with weak contractions in Hadamard manifolds, Linear Nonlinear Anal., 1(2)(2015), 317-328.

[14] C. Li, G. López, V. Martín-Márquez, Monotone vector fields and the proximal point algorithm on Hadamard manifolds, J. Lond. Math. Soc., 79(2009), 663-683.

[15] C. Li, G. López, V. Martín-Márquez, Itetive algorithms for nonexpansive mappings on Hadamard manifolds, Taiwanese J. Math., 14(2)(2010), 541-559.

[16] C. Li, G. López, V. Martín-Márquez, Resolvents of set-valued monotone vector fields in Hadamard manifolds, Set-valued Anal., 19(2011), 361-383.

[17] P.-E. Mainge, A. Moudafi, Strong convergence of an iterative method for hierarchical fixed-points problems, Pacific J. Optim., 3(2007), 529-538.

[18] A. Moudafi, Viscosity approximation methods for fixed-points problems, J. Math. Anal. Appl., 241(2000), 46-55.

[19] S.Z. Németh, Monotonicity of the complementary vector field of a nonexpansive map, Acta Math. Hungar., 84(3)(1999), 189-197.

[20] S.Z. Németh, Monotone vector fields, Publ. Math. Debrecen, 54(1999), 437-449.

[21] S.Z. Németh, Variational inequalities on Hadamard manifolds, Nonlinear Anal., 52(2003), 14911498.

[22] T. Rapcsák, Smooth Nonlinear Optimization in $\mathbb{R}^{n}$, Kluwer Academic Publishers, Dordrecht, 1997.

[23] T. Sakai, Riemannian Geometry, Translations of Mathematical Monographs, Amer. Math. Soc., Providence, RI, 1996.

[24] M. Solodov, An explicit descent method for bilevel convex optimization, J. Convex Anal., 14(2007), 227-237.

[25] C. Udriste, Convex Functions and Optimization Methods on Riemannian Manifolds, Kluwer Academic Publishers, Dordrecht, Boston, London, 1994.

[26] R. Walter, On the metric projections onto convex sets in Riemannian spaces, Arch. Math., XXV(1974), 91-98.

[27] F. Wang, H. Pham, On a new algorithm for solving variational inequality and fixed point problems, J. Nonlinear Var. Anal., 3(2)(2019), 225-233. 
[28] H.K. Xu, Viscosity approximation methods for nonexpansive mappings, J. Math. Anal. Appl., 298(2004), 279-291.

[29] H.K. Xu, Viscosity method for Hierarchical fixed point approach to variational inequalities, Taiwanese J. Math., 14(2)(2010), 463-478.

[30] Y. Yao, Y.J. Cho, Y.C. Liou, Iterative algorithms for hierarchical fixed points problems and variational inequalities, Math. Comput. Model., 52(2010), 1697-1705.

Received: October 24, 2019; Accepted: December 20, 2019. 
